\title{
Phytogenic synthesis of nanoparticles from Rhizophora mangle and their bactericidal potential with DNA damage activity
}

\author{
Baker Syed $^{\mathrm{a}, \mathrm{b}}$, Nalini Bisht ${ }^{\mathrm{a}, 1}$, Prithvi S. Bhat ${ }^{\mathrm{a}, 1}$, Nikhil Karthik R. ${ }^{\mathrm{a}, 1}$, Ashwini Prasad ${ }^{\mathrm{c}}$, \\ Dhananjaya B.L. ${ }^{\mathrm{d}}$, Satish S. ${ }^{\mathrm{e}}$, Hara Prasad ${ }^{\mathrm{a}}$, Nagendra Prasad M.N. ${ }^{\mathrm{a}, *}$
}

a Department of Biotechnology, JSS Science and Technology University, JSS Technical Institutional Campus, Mysore 570006, India

${ }^{b}$ Laboratory of Biotechnology of New Materials Siberian Federal University, Siberia, Russian Federation

${ }^{c}$ Faculty of Life Sciences, Microbiology Department, JSS University, Mysore, India

d Toxicology and Drug Discovery Unit, Centre for Emerging Technologies (CET), Jain University, Ramanagara 562 112, India

e Bionanotechnological Laboratory, Department of Studies in Microbiology, University of Mysore, Manasagangotri, Mysore, India

\section{Keywords: Phytogenic, Rhizophora mangle, Nanoparticles, Bactericidal, DNA damage}

\section{ABSTRACT}

The present study reports phytogenic synthesis of nanoparticles using aqueous extract of Rhizophora mangle. The synthesized nanopartides were characterized using UV-Visible spectroscopy with maximum absorption at $400 \mathrm{~nm}$. Fourier Transform Infrared spectroscopy (FT-IR) studies revealed the presence of functional groups mediating the synthesis of nanoparticles. X-ray diffraction (XRD) displayed Bragg's intensities at $2 \theta$ angle which confirmed the crystalline nature of the nanoparticles. Transmission Electron Microscopy (TEM) revealed size and shape of the nanopartides with polydispersity of nanoparticles and size of 10$60 \mathrm{~nm}$. The synthesized nanoparticles expressed antibacterial activity by well diffusion assay, broth micro dilution assay, minimal inhibitory concentration and CFU assay against selective human pathogens. Nanoparticles were more effective against $S$. aureus (MTCC7443) followed by B. subtilis (MTCC 121). E. coli (MTCC 7410) and S. typhi (MTCC 7407). The possible mode of action of nanopartides was studied by treating silver nanopartides with pathogenic DNA which showed defamed and damage DNA in comparison with control DNA.

\section{Introduction}

Nanoparticles are ultrafine entities with their size less than $100 \mathrm{~nm}$ [1]. In recent years, nanoparticles have gained immense interest due to their remarkable properties compared to their bulk counterpart [2-5]. These unique properties of nanoparticles have resulted in their innumerable applications in diverse fields like semiconductors, fluorescent probes, fuel cells, drug delivery systems, biocatalysts, biosensing and as antimicrobial agents [4]. Rapid expansion in the number of drug resistant microorganisms has resulted in tapping alternative antimicrobial agents and need for viable substitutes to existing antibiotics is one of the top priority research among the scientific communities [5]. The exuberant properties of nanoparticles can be one such alternative to combat drug resistant microorganisms. Synthesizing nanoparticles bearing antimicrobial properties is an exciting area but one of the major constraint includes conventional approaches to synthesize nanoparticles and most of these methods are bound with various limitations $[2,6,7]$. Some of the major limitations include production of environmental pollutants, employment of toxic substances and generation of high energy, thus restricting their application in biomedical sector [8-10]. In order to cope with these limitations, biogenic synthesis of nanoparticles has become the subject of interest among the scientific communities to produce myriad nanoparticles $[4,11,12]$. The biological resources employed in the synthesis may vary from simple prokaryotic organisms to multicellular organisms like plants [11]. Among the 
biological entities, plant mediated synthesis of nanoparticles is a simple and faster process and therefore, there has been tremendous research on plant diversity to synthesize nanoparticles |12]. Some pivotal properties of plants like phytoremediation and phytomining have led to use of plants for the synthesis of nanoparticles [13,14]. Plants are used for the synthesis of nanoparticles is mainly due to presence of phyto-components like amino acids, vitamins, proteins, polysaccharides, polyphenols, organic acids, terpenoids, etc. which bear impact on morphological characteristics of nanoparticles [11,12,15]. Perusal of scientific literature highlights diverse plant species in mediating nanoparticles synthesis and in the present investigation Rhizophora mangle was selected for synthesis of silver nanoparticles. The selection of plant Rhizophora mangle was carried out based on the prior therapeutic index and its existing use in the treatment of wounds, diarrhea, dyspepsia, inflammations, sore throat, eye ailments and epistaxis [16,17].

\section{Materials and methods}

\subsection{Preparation of plant extract}

The Rhizophora mangle belonging to Rhizophoraceae family was selected in the present investigation. Plant material was collected from abundant growing area of Mysuru district of Karnataka, India. Plant materials such as shoot and leaves were washed to remove the adhering soil particles. Further the plant materials were cut into small segments and $20 \mathrm{~g}$ of was ground using a pestle and mortar and boiled in a $250 \mathrm{ml}$ Erlenmeyer flask with $200 \mathrm{ml}$ water for $30 \mathrm{~min}$. The aqueous extract was then used for synthesis of nanoparticles.

\subsection{Synthesis of silver nanoparticles}

The aqueous extract was treated with $1 \mathrm{mM}$ silver nitrate and incubated. Initially synthesis was monitored with change in color of reaction mixture and further confirmation was achieved with UV-Visible spectrophotometry [18]. The conversion of $\mathrm{Ag}^{+}$to $\mathrm{Ag}^{0}$ was measured using Atomic absorption spectroscopy (AAS). Samples were drawn at regular intervals with interval of $5 \mathrm{~min}$ over period of $20 \mathrm{~min}$. The aliquots were centrifuged at 15,000 rpm and the supernatant was assessed for present of silver ions. The rate of decrease in the concentration of silver ions was monitored.

\subsection{Characterization ofnanoparticles}

Samples were drawn and periodically monitored with UV-visible spectroscopy by recording the spectra between 200 and $700 \mathrm{~nm}$ using Shimadzu double beam spectrophotometer. FTIR spectroscopy analysis was carried out to reveal the functional groups in aqueous extract responsible to mediate the synthesis of nanoparticles by using Spectrum Two IR spectrometer (PerkinElmer). The analysis was carried out at room temperature with a resolution of $4 \mathrm{~cm}^{-1}$. Further, in order to determine the crystalline nature of nanoparticles, XRD studies were conducted with Rigaku Miniflex-II Desktop X-ray diffractometer instrument operating ax a voltage of $30 \mathrm{kV}$ and average size was calculated based on Scherrer equation recorded spectra.

$N=K \lambda \beta \cos \theta$. Where $K$ is the Scherrer constant with value from 0.9 to 1 (shape factor), where $\lambda$ is the X-ray wavelength $(1.5418 \mathrm{~A}), \beta 1 / 2$ is the width of the XRD peak at half height and $\theta$ is the Bragg angle. Further size and morphological characteristics of nanoparticles was analyzed by using Transmission Electron Microscopy, where an aliquot of nanoparticles was transferred on to a carbon-coated copper TEM grid. The films on the TEM grids were allowed to stand for $2 \mathrm{~min}$, then extra solution was removed and the grid was allowed to dry prior to measurement and scanned using a TECHNAI-T12 JEOL JEM-2100 Transmission electron microscope operated at a voltage of $120 \mathrm{kV}$ with Bioten objective lens. Subsequently, the particle size was ascertained using a Gatan ccd Camera [18].

\subsection{Bactericidal activity of synthesized nanoparticles}


In order to achieve the bactericidal activity, synthesized nanoparticles were centrifuge at $16,000 \mathrm{rpm}$ for $10 \mathrm{~min}$ which resulted in separation of silver nanoparticles as pellet. The pellet obtained was washed thrice using sterile double distilled water and $10 \mathrm{mg} / \mathrm{ml}$ concentration was obtained and evaluated to antibacterial activity. Bactericidal activity of nanoparticles was carried out with via well diffusion assay, micro broth dilution assay, CFU plate method and minimal inhibitory concentration according to the protocol described by Baker et al. [6]. In brief prewarmed MHA (Mueller-Hinton agar) plates were seeded with $10^{6} \mathrm{CFU}$ (colony forming unit) suspensions of test organism swabbed uniformly, later by using sterile cork borer $10 \mathrm{~mm}$ diameter of agar was punched and $50 \mu \mathrm{l}$ of $10 \mathrm{mg} / \mathrm{ml}$ nanoparticles were added into each well and incubated at $37{ }^{\circ} \mathrm{C}$ for $24 \mathrm{~h}$. After incubation, the zone of inhibition was measured and interpreted with gentamicin at $1 \mathrm{mg} / \mathrm{ml}$ concentration. In CFU assay, inoculum of test pathogens was prepared to obtain $5 \times 10^{5} \mathrm{CFU}$ and bactericidal activity was determined. In brief, MuellerHinton agar plates were supplemented with different nanoparticles concentrations $(25,50,75$ and $100 \mu \mathrm{g} / \mathrm{ml}$ ) and one control was maintained without addition of nanoparticles. The plates were incubated for $24 \mathrm{~h}$ at $37^{\circ} \mathrm{C}$ and colonies were counted and compared with the control plate to determine the effect of nanoparticles. Minimal Inhibitory Concentration was determined by broth micro-dilution technique based on the protocol described by Sarker et al. [19] with slight modification. Resazurin dye was used as a growth indicator to check the efficacy of nanoparticles against the test organisms. Centamicin was used as positive control and bacterial growth in the plate was inspected visually as well as ELISA microtitre plate reader. The possible mode of action and antibacterial potential of synthesized nanoparticles was predicted by treating silver nanoparticles with DNA isolated from against S. aureus (MTCC 7443). DNA with concentration of $10 \mathrm{ng}$ was treated with silver nanoparticles $(10 \mathrm{mg} / \mathrm{ml})$ and incubated for 30 min. DNA without treatment of silver nanoparticles served as a control. Electrophoresis was carried out using $1 \%$ agarose gel at $75 \mathrm{~V}$ for $30 \mathrm{~min}$.

\section{Results and discussion}

The results obtained in the study focus on the importance of synthesis of nanoparticles using plant source. The selection of plant species was carried out based on the traditional knowledge and prior studies on synthesis of nanoparticles. Rhizophora mangle is reported to possess high traditional value which is already well documented in ancient and ayurvedic reports $[16,20]$. Initially, when aqueous plant extract was treated with silver nitrate, reaction was initiated by reduction of metal ions and initial synthesis was confirmed with change in color of the reaction mixture. Further confirmation was attained with UV-Visible spectroscopy which displayed the absorption peak at $400 \mathrm{~nm}$ (Fig. 1 and Supp-1, Appendix A). This red shift in the absorption peaks is due to surface plasmon of synthesized silver nanoparticles [21]. The synthesis of nanoparticles was rapid and completed within 20 min which was measured using atomic absorption spectroscopy (Supp-2, Appendix A). The synthesis was maximum at alkaline $\mathrm{pH}$ and elevated temperature above $70{ }^{\circ} \mathrm{C}$ These results are incongruence with previous findings highlighting the worthiness of the parameters [21]. Interestingly, FTIR reinforced the possible role of phytochemical components responsible for mediating and stabilization the synthesized nanoparticles (Fig. 2) with y-axis being \% transmittance and $\mathrm{x}$-axis being wavenumbers which are proportional to frequencies and these wavenumbers are reciprocal centimeters $\left(\mathrm{cm}^{-1}\right)$. The broad vibrational stretching at 3350 corresponding to $\mathrm{NH}_{2}$ group. Similarly, 1635 corresponds to $\mathrm{CH}_{3}$ and 673 corresponds to $\mathrm{CH}$ functional groups. The FTIR analysis of silver nanoparticles was compared with aqueous plant extract to reveal the functional phyto-components responsible for mediating the synthesis and stabilization of nanoparticles (Supl-3, Appendix A). These results are in accordance with the previous reports highlighting the role of car-bonyl, aliphatic, amide, and aromatic groups facilitating the synthesis and stabilization of nanoparticles [22,23]. The crystalline nature of synthesized nanoparticles was depicted with XRD analysis which exhibited Bragg's intensities reflecting (111), (200), (220) and (311) of the face centered cubic 
structure of silver metal and was compared with standard XRD pattern (Fig. 3). The obtained result justifies with earlier XRD pattern [24]. Transmission electron microscopy revealed the size of nanoparticles in the range of 10-60 nm, the average size being $30 \mathrm{~nm}$ (Fig. 4). The obtained results were incongruence with the previous studies with polydispersity of nanoparticles. The silver nanoparticles displayed polydispersity with various diverse morphological shapes. The bactericidal activity of synthesized nanoparticles resulted in significant activity against all the test pathogens which was measured as zone of inhibition (Table 1 and Supl-5, Appendix A). The broth dilution assay resulted in drastic decrease in the optical density of test pathogens as silver nanoparticles concentration was increased (Supl-4, Appendix A). Similarly, colony forming unit displayed decrease in the density of viable colonies as silver nanoparticles concentration increased from 0 to $100 \mathrm{u} . \mathrm{g} / \mathrm{mL}$ The results of both broth dilution and CFU were inaccordance with well diffusion assay (Supl-5, Appendix A).

Further, the minimal inhibitor concentration displayed activity in the range of 31.25-125 $\mu \mathrm{g} / \mathrm{ml}$. The results with different antibacterial assays were consistent with highest activity being recorded against Staphylococcus aureus (MTCC 7443) followed by Bacillus subtilis (MTCC 121), Escherichia coli (MTCC 7410) and Salmonella typhi (MTCC 7407). The results obtained in this study justifies with the earlier reports which centralized the assessment of silver nanoparticles as potent antibacterial agents $[25,26]$. The obtained results were interpreted with positive control Centamicin. In recent times there is rapid expansion of drug resistant pathogenic bacteria. In order to combat drug resistant pathogens, scientific communities are engaged in developing alternative strategies. One such alternative strategy includes combination or conjugation of nanoparticles with antibiotics which results in increase fold dilution of the activity [27]. Hence in the present investigation, initial attempt was carried out to synthesize silver nanoparticles from aqueous extract of Rhizophora mangle. Further, the possible mode of action of synthesized nanoparticles on DNA isolated from Staphylococcus aureus (MTCC 7443). Silver nanoparticles treated with DNA exhibited defamed and damage property in comparison with the control DNA without treatment of silver nanoparticles (Fig. 5). Overall, the results of present investigation is sufficiently promising and contribute towards the expanding literature on phytogenic mediated nanoparticles as facile single step protocol which can overcome the limitations posed by conventional protocols in synthesis of nanoparticles.

\section{Conclusion}

This investigation contribute towards phytogenic synthesis of silver nanoparticles. The results reveal the potential of Rhizophora mangle for rapid synthesis of silver nanoparticles. The synthesized silver nanoparticles displayed substantial bactericidal activity against selected human pathogens. The obtained results emphasize the role of silver nanoparticles as potent substitutes to conventional antibiotics in order to combat the multi-drug resistance of pathogenic microorganisms.

\section{Acknowledgments}

Authors have no conflict of interest and are pleased to thank ICMR for financial assistance. We also like to thank SibFU (5-100), Siberian Federal University for Young scientist award. Authors thank principal and Management of JSS Science and Technical University for providing lab facilities. Authors are also grateful to Prof. Sridhar M. A., Latha Rani and Ceetha D. V, Department of Physics, University of Mysore for XRD analysis.

\section{References}

[1] P. Banerjee, M. Satapathy, A. Mukhopahayay. P. Das. Leaf extract mediated green synthesis of silver nanoparticles from widely available Indian plants: synthesis, characterization, antimicrobial property and toxicity analysis, Bioresour. Bioprocess. 1 (2014) 1-10.

[2] M. Forough, 1C Fahadi, Biological and green synthesis of silver nanoparticles, Turkish J. Eng. Environ- Sci. 34 (2011) 281-287. 
[3] R. Prasad, Synthesis of silver nanoparticles in photosynthetic plants, J.

\section{Nanopart. 2014 (2014) 8. Article ID 963961.}

[4] M. Shah, D. Fawcett, S. Sharma, S.K. Tripathy, C.E.J. Poinern, Green synthesis of metallic nanoparticles via biological entities, Materials 8 (2015) 7278-7308.

[5] J. Perez, L. Bax, C Escolano, Roadmap Report on Nanoparticles, Willems \& Van

Den Wildenberg, Barcelona, Spain, 2005.

[6] S. Baker, A. Pasha, S. Satish, Biogenic nanoparticles bearing antibacterial activity and their synergistic effect with broad spectrum antibiotics: Emerging strategy to combat drug resistant pathogens, Saudi, Pharmacol. J. (2015) http://dx.doi.Org/10.1016/j.jsps.2015.06.0U.

[7] F. Okafor, A. Janen, T. Kukhtareva, V. Edwards, M. Curley, Green synthesis of silver nanoparticles, their characterization, application and antibacterial activity, Int. J. Environ. Res. Public Health 10(2013) 5221-5238.

[8] A. Mubayi, S. Chatterji, P.M. Rai, G. Watal, Evidence based green synthesis of nanoparticles. Adv. Mater. Lett. 3 (2012) 519-525.

[9] X. Li, H. Xu, Z.S. Chen, G. Chen, Biosynthesis of nanoparticles by microorganisms and their applications, J. Nanomater. 2011 (2011)270974.16 pages.

[10] S. Ponarulselvam, C Panneerselvam, K. Murugan, N. Aarthi, K. Kalimuthu, S. Thangamani, Synthesis of silver nanoparticles using leaves of Caiharamhus roseis Linn. G. Don and their antiplasmodial activities, Asian. Pac. J. Trop. Biomed. 2 (2012) 574-580.

[11] S. Baker, D. Rakshith, K.S. Kavitha, P. Santosh, H.U. Kavitha, Y. Rao, S. Satish, Plants: emerging as nanofactories towards facile route in synthesis of nanoparticles, Bioimpacts $3(2013) 111-117$.

[12] N. Kulkarni, U. Muddapur, Biosynthesis of metal nanoparticles: a review, J. Nanotechnol. 2014 (2014) 510246.8 pages.

[13] 0. Collera-Zuniga, F.G.Jimenez, R.M. Gordillo, Comparative study of carotenoid composition in three mexican varieties of Capsicum annuиm L, Food Chem. 90 (2005)109-114.

[14] N.Ahmad, S. Sharma, Green synthesis of silver nanoparticles using extracts of Ananascomosus, Green, Sustain. Chem. (2012) 141-147.

[15] S. Ahmed, M. Ahmad, B.L Swami, S. Ikram, A review on plants extract mediated synthesis of silver nanoparticles for antimicrobial applications: a green expertise, J. Adv. Res. 7 (2016) 17-28.

[16] B. Berenguer, LM. Sanchez, A. Quilez. M. Lopez-Barreiro, 0. De Наго,J. Galvez, M.J. Martin, Protective and antioxidant effects of Rhizophora mcmgte L against NSAID-induced gastric ulcers, J. Ethnopharmacol. 103(2006) 194-200.

[17] J.F. Morton, Atlas of medical plants of Middle America, Bahamas to Yucatan, Charles C. Thomas Publ.. USA. 1981.

[18] D. Mandal, M.E. Bolander, D. Mukhopadhyay, G. Sarkar, P. Mukheriee. The use of microorganisms for the formation of metal nanoparticles and their application, Appl. Microbiol. Biotechnol.69(2006)485-492.

[19] S.D. Sarker, L Nahar, Y. Kumarasamy, Microtitre plate-based antibacterial assay incorporating resazurin as an indicator of cell growth, and its application in the in vitro antibacterial screening of phytochemicals. Methods 42 (2007) 321-324.

[20] J.T. Roig y Mesa, A.D.C. de Cuba, Plantasmedicinales, aromaticas o venenosas deCuba-2 (1974). |

[21] S. Baker, K.M. Kumar, P. Santosh, D. Rakshith, S. Satish, Extracellular synthesis of silver nanoparticles by novel Pseudomonas veronii AS41G inhabiting Annona squamosa $\mathrm{L}$ and their bactericidal activity, Spectrochim. Acta Part A Mol. Biomol. 136(2015) 1434-1440.

[22] S. Ahmed, S. Ikram, Silver nanoparticles: one pot green synthesis using Terminaiia arjuna extract for biological application, J. Nanomed. Nanotechnol. 6(2015) 4.

[23] P.S. Praba, V.S. Vasantha. J. Jeyasundari, Y.BA. Jacob. Synthesis of plant-mediated silver nanoparticles using Ficus microcarpo leaf extract and evaluation of their antibacterial activities. Eur. Chem. Bull. 4(2015) 117-120. 
[24] L Christensen, S. Vivekanandhan, M. Misra. A.K. Mohanty. Biosynthesis of silver nanoparticles usingMurraya koenigii (curry leaf): an investigation on the effect of broth concentration in reduction mechanism and particle size, Adv. Mat. Lett. 2 (2011) 429-434.

[25] S. Maiti, D. Krishnan, G. Barman, S.K. Ghosh. J.K. Laha, Antimicrobial activities of silver nanoparticles synthesized from Lycopersicon esculentum extract, J.Anal.Sci.Technol.5(2014) 1-7.

[26] S.H. Kim. H.S. Lee, D.S. ftyu, S.J. Choi. DS. Lee. Antibacterial activity of silverronoparacles against Staphylococcus aureus and Escherichia cofi. Korean, J. Microbiol. Biotechnol. 39 (2011) 77-85.

[27] B. Syed, M.N. Nagendra Prasad, B.L DhananJaya, K. Mohan Kumar, S. Yallappa. S. Satish. Synthesis of silver nanoparticles by endosymbiont Pseuuomonos fiuorescens CA 417 and their bactericidal activity. Enzyme Microb. Technol. 95 (2016)128-136. 
275 Fig. 1. UV-Visible spectra of silver nanoparticles synthesized by Rhizophora mangle

276 Fig. 2. FTIR analysis of silver nanoparticles synthesized by Rhizophora mangle

277 Fig. 3. XRD analysis of silver nanoparticles synthesized by Rhizophora mangle

278 Fig. 4. TEM analysis of silver nanoparticles synthesized by Rhizophora mangle

279 Fig. 5. DNA damage activity of silver nanoparticles synthesized by Rhizophora mangle

280

281 
282 Table 1 Mean zone of inhibition $(\mathrm{mm})$ of antibiotic gentamicin, silver nanoparticles, silver 283 nitrate, plant extract

284

\begin{tabular}{lllll}
\hline Pathogens & Gentamicin & $\begin{array}{l}\text { Phyto-biologic } \\
\text { synthesized } \\
\text { nanoparticles }\end{array}$ & Silver nitrate & Aqueous extract \\
\hline B.subtilis & 24 & 12 & - & - \\
\hline E.coli & 24 & 08 & 03 & - \\
\hline S.aureus & 21 & 09 & - & - \\
\hline S.typhi & 12 & 08 & 02 & - \\
\hline
\end{tabular}

285

286

287

288

289 


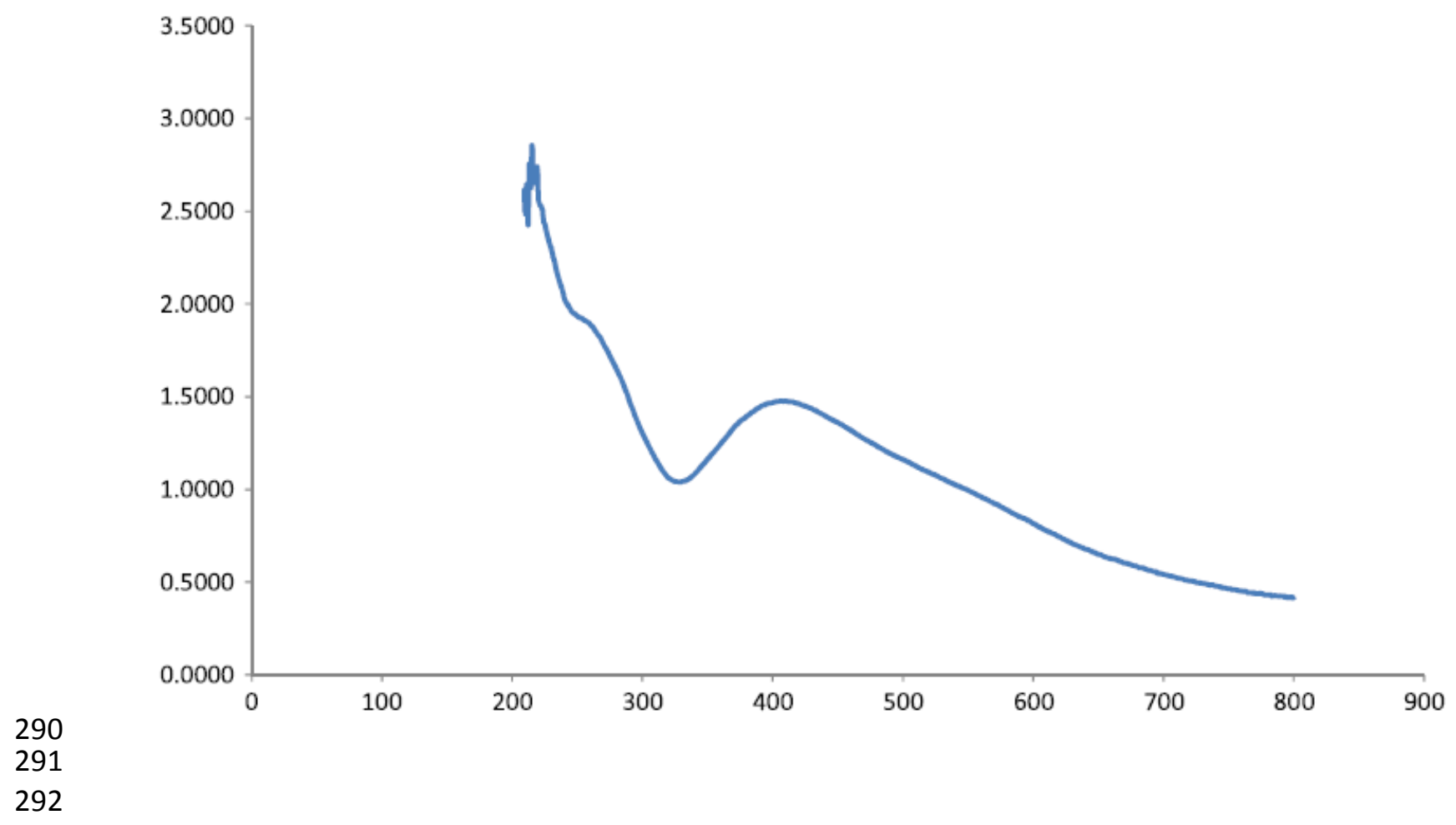




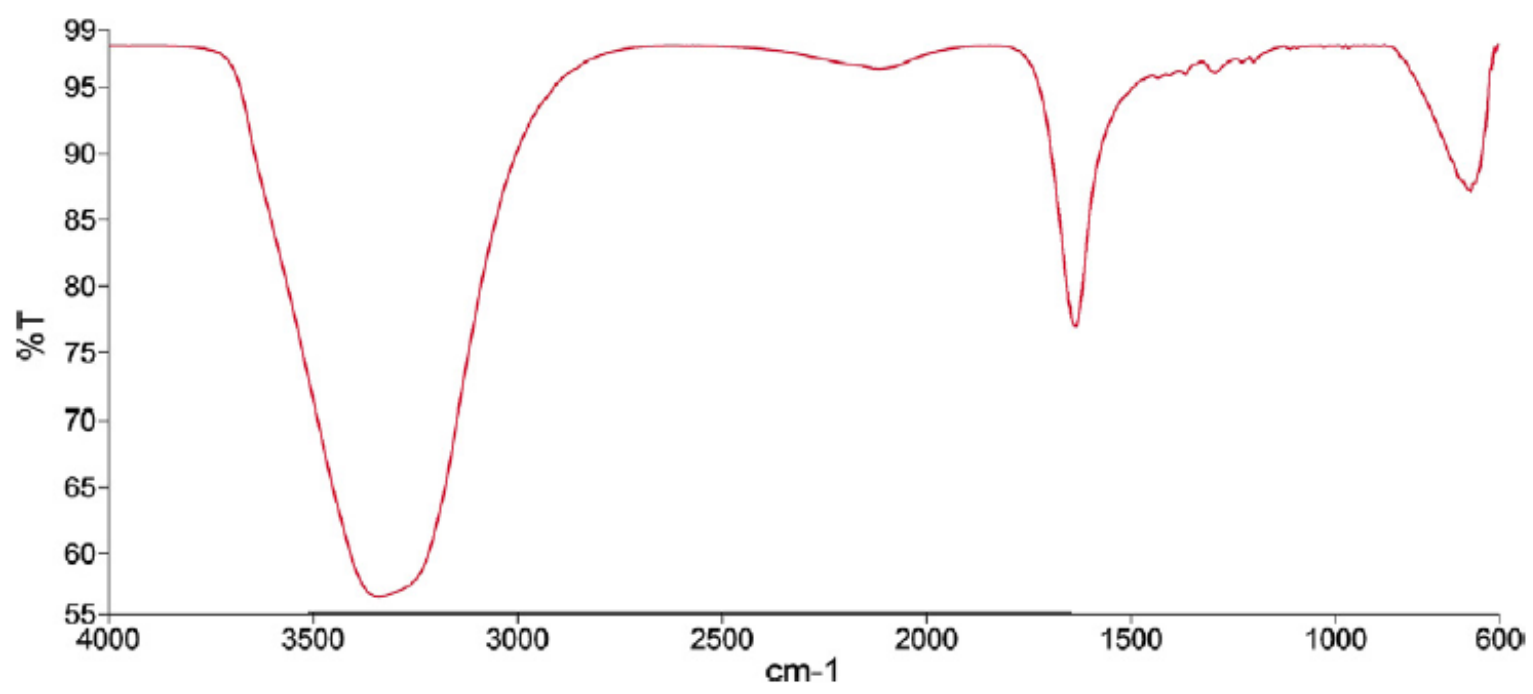

293

294 


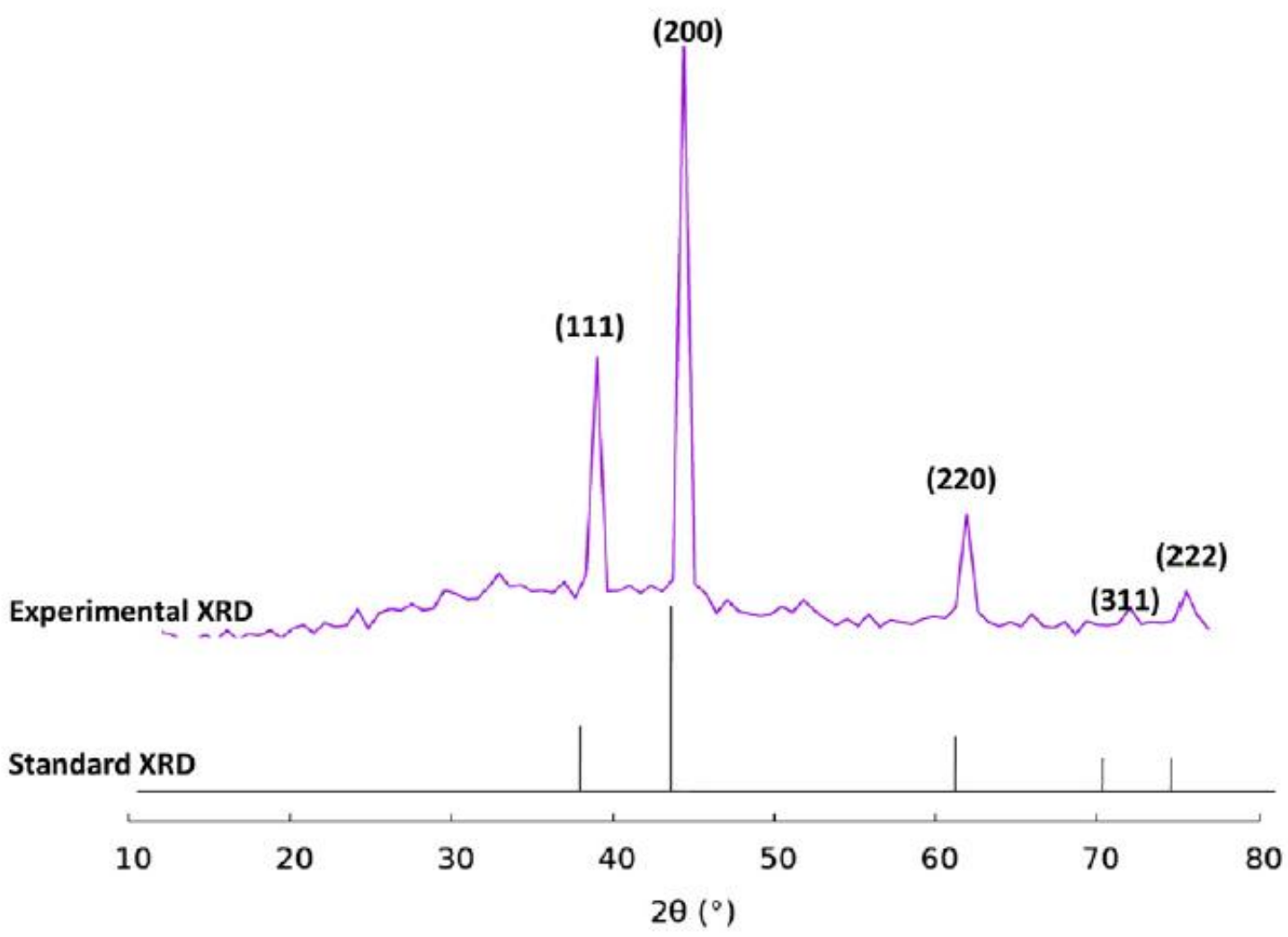




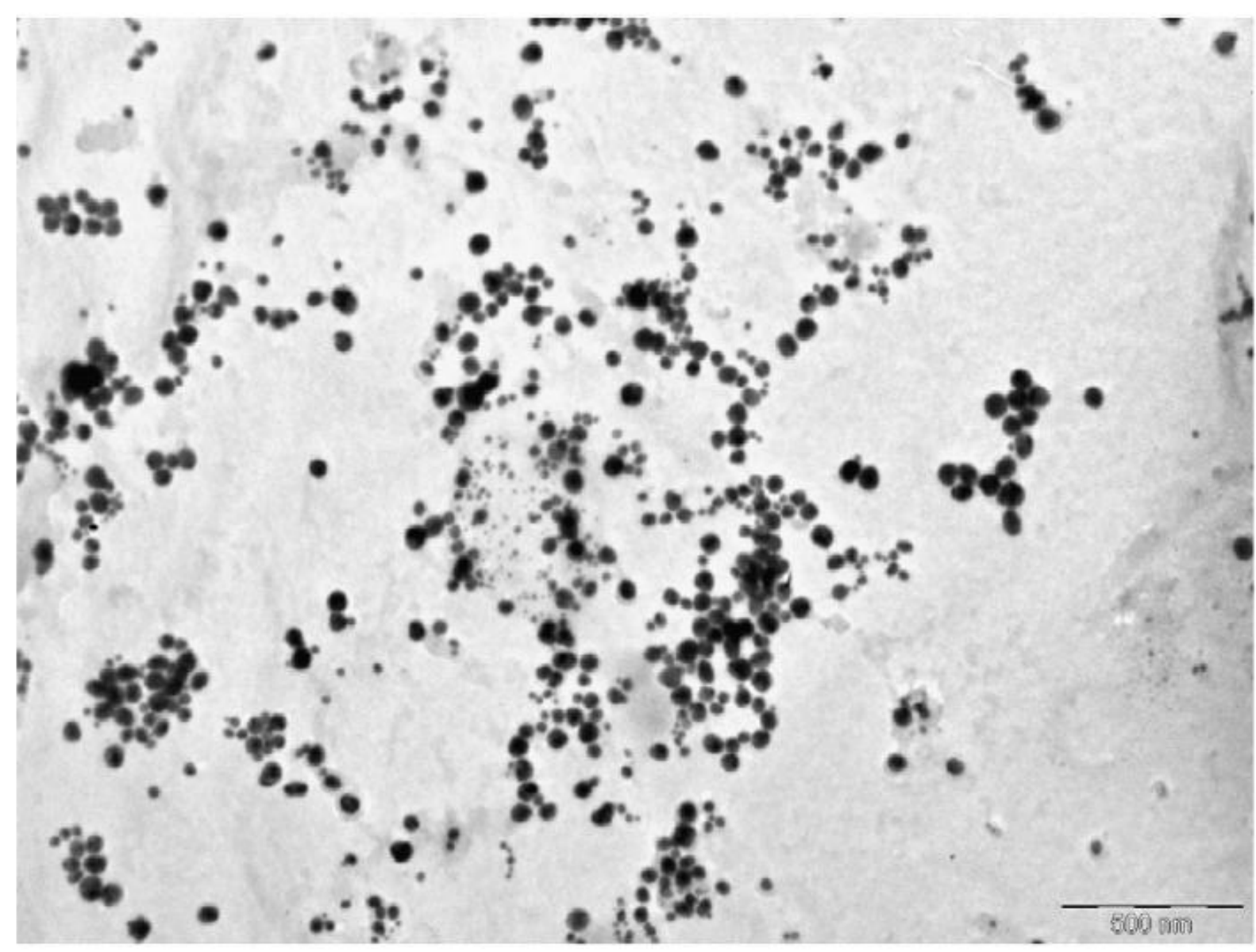


Control DNA

300
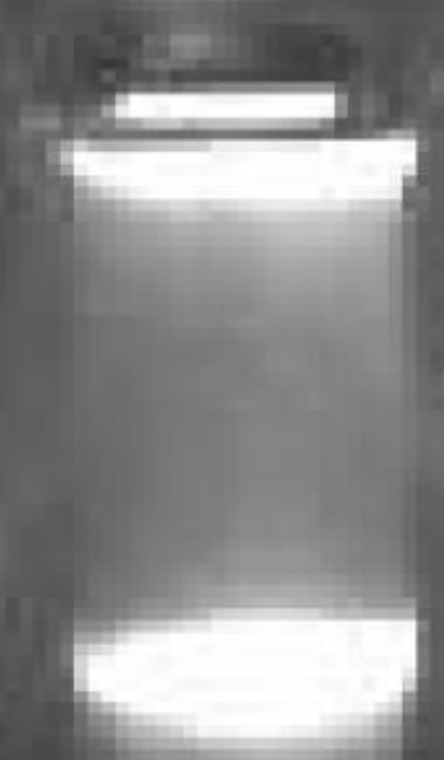

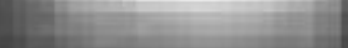

SNP

DNA
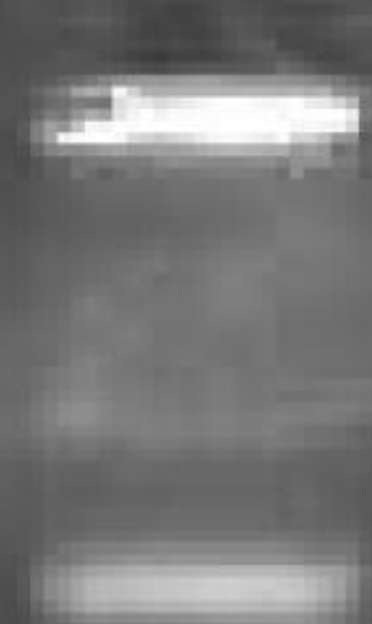